\title{
Potent attenuation of context fear by extinction training contiguous with acquisition
}

\author{
Brian E. Bernier, ${ }^{1,2}$ Anthony F. Lacagnina, ${ }^{1,2}$ and Michael R. Drew ${ }^{1}$ \\ ${ }^{1}$ Center for Learning and Memory, Department of Neuroscience, University of Texas at Austin, Austin, Texas, 78712, USA
}

\begin{abstract}
Studies on the behavioral mechanisms underlying contextual fear conditioning (CFC) have demonstrated the importance of preshock context exposure in the formation of aversive context memories. However, there has been comparatively little investigation of the effects of context exposure immediately after the shock. Some models predict that nonreinforced context exposure at the end of the acquisition session will strongly influence the strength of conditioning and/or recruit distinct neural mechanisms relative to extinction after acquisition. Here we investigate the effects of manipulating postshock context exposure on CFC in mice. Prolonging the period of context exposure immediately following the shock caused a significant and durable reduction in conditioned fear. This immediate postshock context exposure was more effective at attenuating conditioned fear than was an equivalent amount of context exposure a day or more after acquisition. The results suggest that nonreinforced exposure to the context influences conditioned fear through distinct mechanisms depending on whether it occurs during acquisition or after it. The superiority of immediate postshock context exposure was specific to single-shock CFC; in two-shock CFC, immediate and delayed postshock context exposure had similar effects. Consistent with previous reports, we hypothesize that the effectiveness of extinction is modulated by emotional state, and procedures engendering higher postshock freezing (such as two-shock CFC) are associated with weaker immediate extinction.
\end{abstract}

Contextual fear conditioning (CFC) is a form of associative learning that occurs when an aversive experience, usually a footshock in laboratory experiments, occurs within a distinctive place or context. Learned contextual fear typically recruits plasticity in the hippocampus, which is thought to generate a conjunctive mnemonic representation of stimuli present during the learning episode (Rudy et al. 2004; Fanselow 2010). The robustness of this form of learning has made it one of the preferred methods for studying mechanisms of hippocampus-dependent memory and learned fear.

While the neural mechanisms of CFC have been researched extensively, there has been comparatively little investigation of the behavioral mechanisms through which the emotional valence of a context is established. One longstanding idea is that the strength of context conditioning is determined by the overall rate of unconditioned stimulus (US) presentation per unit time in the context (Rescorla and Wagner 1972; Gibbon and Balsam 1981). This approach accounts for the observation that increasing the intertrial interval in conditioning experiments tends to decrease the amount of conditioned responding elicited by the context (Fanselow et al. 1993; Barela 1999). However, this model fails to account for a key property of CFC: very brief preshock context exposure leads to an absence of context fear, rather than robust fear as the rate-based model would predict (Fanselow 1986). This phenomenon, known as the immediate shock deficit, has led to the idea that preshock context exposure strengthens CFC because it enables the animal to generate a mental representation of the context, which can then become associated with the shock (Rudy et al. 2002). More generally, the immediate shock deficit demonstrates that all epochs within the conditioning session do not have equal sway over the outcome of conditioning.

Less attention has been paid to the role of context exposure at the end of a conditioning session. Yet there is reason to predict that postshock context exposure should strongly influence the

\section{${ }^{2}$ These authors contributed equally to this work.} Corresponding author: drew@mail.clm.utexas.edu

Article is online at http://www.learnmem.org/cgi/doi/10.1101//m.036673.114. emotional status of a context. Experiments in humans indicate that the emotional evaluation of a remembered event is dominated by the subject's emotional status at the end of the event, a property that has been formalized in the peak-end model of memory (Kahneman et al. 1993). For instance, adding a period of reduced discomfort at the end of an aversive experience (e.g., colonoscopy or exposure to freezing cold water) attenuates the remembered aversiveness of the experience despite extending the total duration of the experience (Varey and Kahneman 1992; Redelmeier et al. 2003). The influence of postshock context exposure is also supported by the "state classification" model (Redish et al. 2007; Gershman et al. 2010, 2013), which predicts that integrating acquisition and extinction into a single session should encourage integration of acquisition and extinction memories, effectively leading to a stronger and/or permanent form of extinction. Finally, the interval between acquisition and extinction has been hypothesized to influence the effectiveness of extinction. Pavlov (1927) was the first to suggest that recently formed associations should be more readily extinguished. Consistent with this prediction, there is evidence that fear memories in a labile state due to recent acquisition (Myers et al. 2006) or recent retrieval (Monfils et al. 2009; Schiller et al. 2010) are especially susceptible to extinction, although the literature regarding these phenomena is mixed (Chan et al. 2010; Stafford et al. 2013; for review, see Maren 2014). To our knowledge, the effect on fear conditioning of variation in the amount of postshock context exposure within the same session as acquisition has not been investigated parametrically (but see Kiernan et al. 1995; Lattal and Abel 2001).

Here we investigate the effect of postshock context exposure in single-footshock CFC in mice. We show that a brief period of context exposure immediately after the footshock can cause a

(C) 2014 Bernier et al. This article is distributed exclusively by Cold Spring Harbor Laboratory Press for the first 12 months after the full-issue publication date (see http://learnmem.cshlp.org/site/misc/terms.xhtml). After 12 months, it is available under a Creative Commons License (Attribution-NonCommercial 4.0 International), as described at http://creativecommons.org/ licenses/by-nc/4.0/. 
strong and long-lasting reduction in conditioned fear. The effect of this immediate postshock context exposure is significantly stronger than that of the same amount of context exposure occurring a day or more after conditioning. The results are consistent with the idea that nonreinforced exposure to the context influences conditioned fear through distinct mechanisms depending on whether it occurs during acquisition or after it.

\section{Results}

Extending the postshock interval reduces conditioned fear We began by exploring whether postshock context exposure within the conditioning session affects CFC. Groups of mice were conditioned with a single shock $180 \mathrm{sec}$ after being placed into the conditioning chamber and were left in the chamber for various intervals afterward. Conditioned contextual fear was tested $24 \mathrm{~h}$ later by returning mice to the conditioning chamber for $5 \mathrm{~min}$ (Fig. 1A). Mice that received postshock intervals of 10 or 30 sec displayed moderate levels of freezing to the shock context, but those receiving postshock intervals of 210 or $600 \mathrm{sec}$ displayed very little freezing behavior (Group $\times$ Time interaction: $F_{(12,88)}=4.98, P<$ 0.001). Post hoc pairwise comparisons (Holm-Sidak, $P<0.05$ ) confirmed group differences in freezing levels during each of the first $3 \mathrm{~min}$ of the test session (Fig. 1B). Because freezing declined over the course of the test session, possibly due to within-session extinction or temporal specificity of freezing (Bevins and Ayres 1995), we separately analyzed the asymptotic freezing levels by computing the mean freezing over the first 2 min of the test session, during which freezing was maximal in all groups (Fig. 1C). A one-way ANOVA reveals a significant effect of postshock inter-

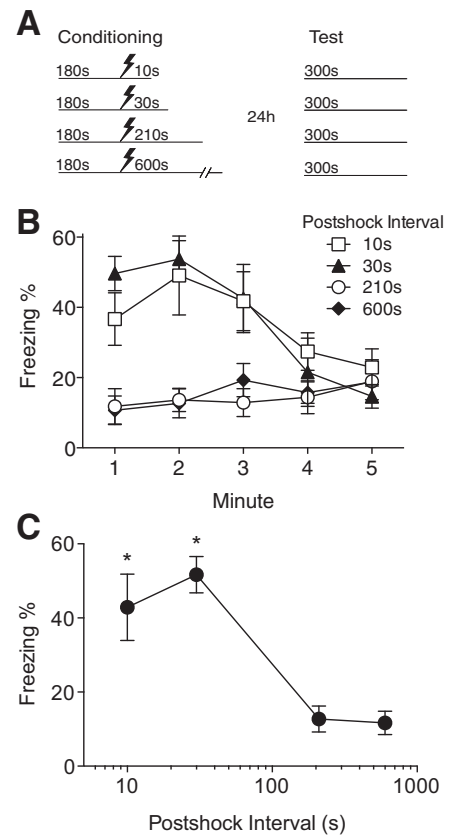

Figure 1. Postshock interval strongly influences contextual fear conditioning. (A) Experimental design. (B) Time course of freezing behavior during context test. Mice receiving postshock intervals of 210 or 600 sec exhibited significantly less freezing than those receiving 10 or 30 sec of postshock exposure. (C) Asymptotic freezing levels (mean freezing during the first 2 min of the context test) were strongly affected by the postshock interval. Values are mean percent freezing \pm SEM; $\left(^{*}\right) P<$ 0.05 compared with 210 and 600 -sec postshock groups (10-sec group: $n=8,30$-sec group: $n=5,210$-sec group: $n=5,600$-sec group: $n=8$ ). val $\left(F_{(3,22)}=9.94, P<0.001\right)$, with higher freezing in animals receiving 10- or 30-sec postshock exposure compared with 210- or 600-sec postshock exposure.

In the previous experiment the postshock interval was confounded with total session duration. If total session time is the critical variable, then variation in the preshock interval duration should have similar effects to variation in the postshock interval. To test this hypothesis, we delivered a single shock to mice using $2-, 10-, 180-$, or 600-sec preshock intervals, followed by either a 30or 210 -sec postshock interval. Mice were then tested for context fear $24 \mathrm{~h}$ later. Figure 2 shows percent freezing as a function of time during the 5 min test session (Fig. 2A-D). Consistent with a variety of other studies demonstrating the immediate shock deficit (Blanchard et al. 1976; Fanselow 1986, 1990; Kiernan and Cranney 1992; Westbrook et al. 1994; Bevins and Ayres 1995), the shortest preshock interval ( $2 \mathrm{sec}$ ) produced very low levels of freezing in the context test regardless of the postshock duration (Fig. $\left.2 \mathrm{~A} ; F_{(1,15)}=0.01\right)$. However, when the preshock interval was $10 \mathrm{sec}$ or longer, the strength of conditioning was influenced by the postshock interval, with greater freezing in the 30 -sec postshock groups compared with 210-sec groups (Fig. 2B-D; 10 secpostshock interval $\times$ time interaction: $F_{(4,44)}=8.11, P<0.001$; 180 sec-main effect of postshock interval: $F_{(1,25)}=4.44, P=$ $0.045 ; 600$ sec-Postshock Interval $\times$ Time interaction: $F_{(4,56)}=$ $8.21, P<0.001)$.

To compare the effect of the postshock interval on freezing levels across different preshock intervals, we computed the mean freezing during the first 2 min of the context test and compared these to the 2-sec preshock groups, which displayed minimal freezing consistent with the immediate shock deficit (Fig. $2 \mathrm{E})$. Since the postshock interval had no effect on freezing at the 2-sec preshock interval, animals from this treatment were pooled for analysis. At all other preshock intervals examined (10, 180, and $600 \mathrm{sec}$ ), mice that received 30 sec of postshock context exposure froze significantly more than those receiving an immediate shock $\left(F_{(3,40)}=6.29, P=0.001\right)$. In contrast, among mice receiving 210 sec of postshock context exposure, freezing did not exceed immediate shock levels regardless of preshock interval $\left(F_{(3,42)}=\right.$ $1.72, P=0.177)$. These results replicate our initial findings in Figure 1 and illustrate that the preshock and postshock intervals have different effects on conditioned fear.

\section{Immediate postshock context exposure more effectively reduces conditioned fear than delayed context exposure} The postshock interval in CFC represents a period of nonreinforced exposure to the context. As such, the effects of prolonging postshock context exposure may simply reflect extinction of the conditioned response (CR). We compared the putative extinction induced during the postshock period to that induced during a separate period of context exposure occurring $24 \mathrm{~h}$ after the training session. To control for the effects of handling, an additional group was handled $30 \mathrm{sec}$ after the shock and then returned to the conditioning chamber $1 \mathrm{~min}$ later. All mice received a total of $210 \mathrm{sec}$ of postshock context exposure. In Group Contiguous this exposure occurred within the same session as the shock. Group $24 \mathrm{~h}$ was removed from the conditioning chamber $30 \mathrm{sec}$ after the shock and then received the remaining $180 \mathrm{sec}$ of context exposure $24 \mathrm{~h}$ later. Group Handled received 30 sec of postshock context exposure, was removed from the conditioning chamber for 1 min, and then returned for the remaining 180 sec of context exposure. This design allows us to test the effects of context exposure occurring at different times relative to shock (Fig. 3A).

Figure 3B plots the time course of freezing during the 180-sec context exposure and a 5-min test session $24 \mathrm{~h}$ later. The 180 -sec context exposures occurred at different times following US 
A
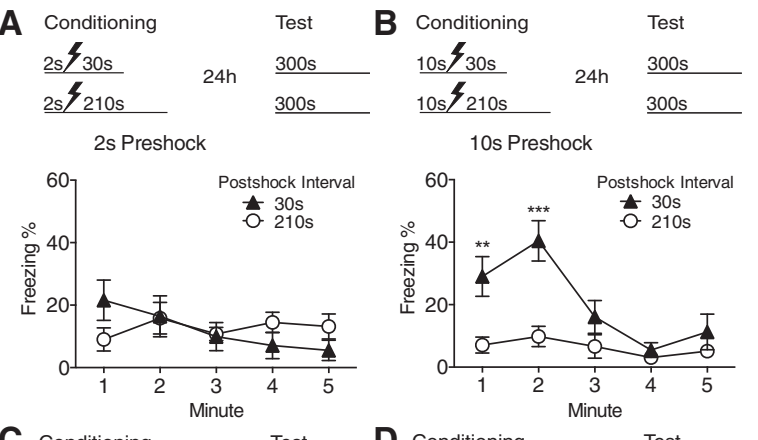

10s Preshock

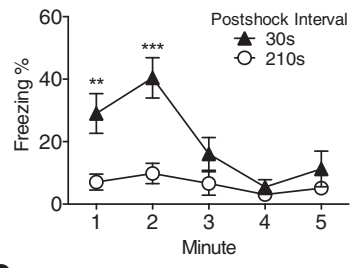

c

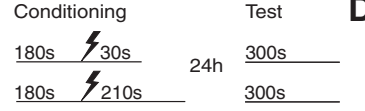

180s Preshock
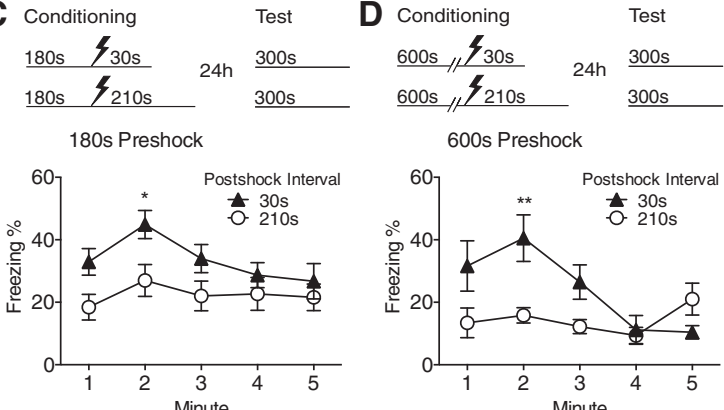

600 s Preshock

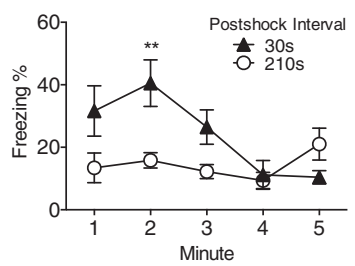

E

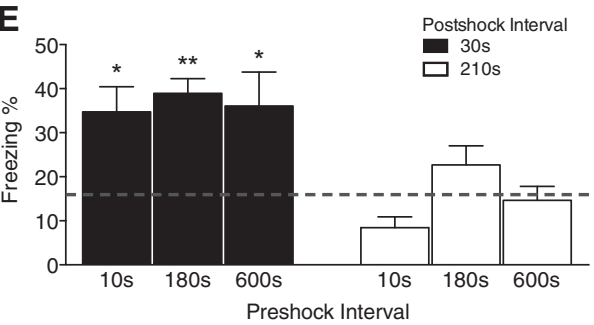

Figure 2. Preshock and postshock intervals have different effects on conditioning $(A-D)$ Time course of freezing behavior during the context test for groups conditioned with various preshock and postshock intervals. (A) The shortest preshock interval $(2 \mathrm{sec})$ produced little conditioned freezing regardless of postshock interval. With preshock intervals of 10 $(B), 180(C)$, or $600 \mathrm{sec}(D)$ the strength of conditioning was strongly influenced by the postshock interval. In each of these groups, mice receiving $210 \mathrm{sec}$ of postshock exposure displayed less conditioned fear than those receiving $30 \mathrm{sec}$ of postshock exposure. (E) Asymptotic freezing (first 2 min of context test) as a function of the pre- and postshock intervals. The gray dashed line represents the mean of the 2-sec preshock groups (values pooled from both postshock treatments). At preshock intervals of 10,180, and $600 \mathrm{sec}$, mice with a 30 -sec postshock interval froze significantly more than those receiving a 2 -sec preshock interval (i.e., "immediate shock"), while freezing in mice with a 210 -sec postshock interval did not differ from immediate shock levels. Values are mean percent freezing $\pm \mathrm{SEM} ;\left(^{*}\right) P<0.05,\left(^{* *}\right) P<0.005$, (**) $P<0.001$ (2-sec/30-sec group: $n=9$, 2-sec/210-sec group; $n=8,10-\mathrm{sec} / 30$-sec group: $n=6,10-\mathrm{sec} / 210-\mathrm{sec}$ group: $n=7,180-\mathrm{sec} / 30-\mathrm{sec}$ group: $n=$ 13, $180-\mathrm{sec} / 210-\mathrm{sec}$ group: $n=14,600-\mathrm{sec} / 30-\mathrm{sec}$ group: $n=8$, 600-sec/210-sec group: $n=8$ ).

delivery in each group but are overlaid for simplicity. Group $24 \mathrm{~h}$ displayed higher levels of freezing across the entire extinction session than Groups Contiguous and Handled (Group $\times$ Time interaction: $\left.F_{(4,66)}=2.59, P=0.045\right)$, presumably reflecting fear incubation over the $24 \mathrm{~h}$ after training (Bindra and Cameron 1953; Kamin 1957).

During the test session, the timing of postshock exposure influenced the magnitude of conditioned freezing (main effect of Group: $\left.F_{(2,33)}=4.407, P=0.02\right)$. A post hoc test comparing group differences revealed Group $24 \mathrm{~h}$ displayed greater freezing than Group Contiguous, and the difference with Group
Handled approached significance $(P=0.065)$. As in the previous experiments, we compared asymptotic freezing levels by taking the mean freezing for the first 2 min of the test session (Fig. 3C). This analysis confirmed Group $24 \mathrm{~h}$ froze significantly more than Groups Contiguous and Handled $\left(F_{(2,33)}=5.55, P=0.008\right)$, which were both equivalently low. These results suggest that (1) the timing and not simply the total amount of postshock exposure determines the final level of conditioned fear, (2) nonreinforced context exposure immediately after conditioning produces a greater reduction in conditioned fear than does an equivalent amount of context exposure on the following day, and (3) the effects of immediate postshock context exposure are not explained by handling effects related to removal of mice from the conditioning chamber shortly after the shock.

\section{Extended postshock exposure suppresses but does not erase conditioned fear}

Immediate extinction training can in some cases cause a suppression of the conditioned response that is resistant to spontaneous recovery, renewal, and reinstatement (Myers et al. 2006), three manipulations that are usually sufficient to recover the CR after delayed extinction. Resistance to these forms of recovery suggests that immediate extinction induces a more robust and persistent suppression of the CR than delayed extinction. We asked whether postshock context exposure produces a more persistent loss of conditioned fear than delayed context exposure. Mice were conditioned with a single shock and then received either 30 or $210 \mathrm{sec}$ of postshock context exposure. Then, $7 \mathrm{~d}$ later, mice were given a series of daily extinction sessions until the 30- and 210-sec groups reached similarly low levels of conditioned freezing. We then assessed savings by reconditioning mice with a single shock in the same chamber. Mice were tested for context fear $24 \mathrm{~h}$ after reconditioning (Fig. 4A). To control for effects of context exposure, we included a context-alone group that received the same context exposure as the 210 -sec group but did not receive a shock during the first conditioning session. To the extent that the original contextUS association remained intact after extinction in Groups 30 and $210 \mathrm{sec}$, these groups should display increased freezing compared with the Group Context Alone (which received its first shock during the reconditioning session) during the final test session.
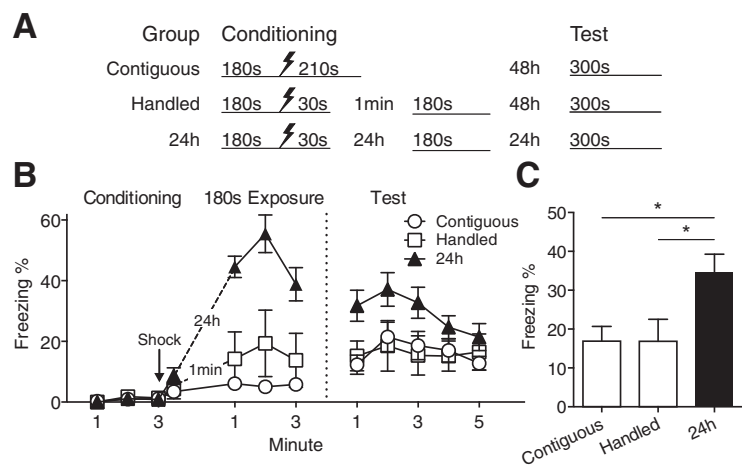

Figure 3. Immediate postshock context exposure more effectively reduces contextual fear than delayed context exposure. (A) Experimental design. (B) Time course of freezing behavior during all phases of the experiment. During both the postshock exposure and the context test, mice receiving delayed postshock exposure (Group $24 \mathrm{~h}$ ) displayed more freezing than groups receiving either within-session (Group Contiguous) or immediate (Group Handled) postshock exposure. (C) Asymptotic freezing during the context test was highest in Group 24 h. Groups Contiguous and Handled did not differ from each other. Values are mean percent freezing \pm SEM; $\left({ }^{*}\right) P<0.05$ (Group Contiguous: $n=15$, Group Handled: $n=7$, Group 24 h: $n=14$ ). 


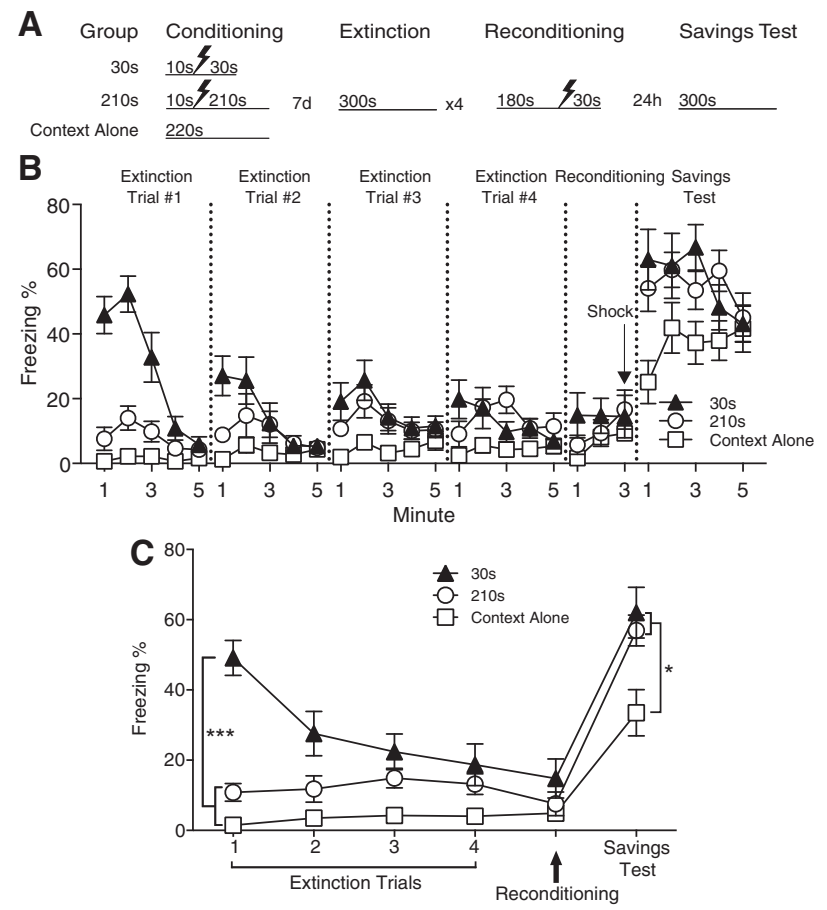

Figure 4. Mice receiving immediate postshock context exposure display savings when reconditioned. $(A)$ Experimental design. (B) Time course of freezing behavior during extinction, reconditioning, and the context test. Group $210 \mathrm{sec}$ exhibited significantly less freezing than Group $30 \mathrm{sec}$ on days 1 and 2 of extinction. Group $210 \mathrm{sec}$ did not differ from Group Context Alone on any day of extinction. On the final day of extinction, freezing levels did not differ among the three groups. In the context test following reconditioning, Groups 30 and $210 \mathrm{sec}$ exhibited significantly more freezing than Group Context Alone. Values are mean percent freezing $\pm \operatorname{SEM} ;\left(^{*}\right) P<0.05,\left({ }^{* *}\right) P<0.001$ (Group 30 sec: $n=8$, Group $210 \mathrm{sec} n=8$, Group Context Alone: $n=7)$. (C) Asymptotic freezing was significantly higher in Group $30 \mathrm{sec}$ compared to Groups $210 \mathrm{sec}$ and Context Alone during the first extinction session. Following reconditioning, asymptotic freezing in Groups 30 and 210 sec was equivalently higher than Context Alone.

During the first test of conditioned fear $7 \mathrm{~d}$ after training, mice receiving $30 \mathrm{sec}$ of postshock exposure displayed significantly higher levels of freezing in the first $3 \mathrm{~min}$ than those receiving $210 \mathrm{sec}$ of postshock exposure or no conditioning (Fig. 4B; Group $\times$ Time interaction: $\left.F_{(8,80)}=10.53, P<0.001\right)$. This replicates results in Figure 2 and indicates that the effect of postshock context exposure is not merely a temporary suppression of conditioned fear. Over the course of daily extinction sessions, freezing in Group $30 \mathrm{sec}$ gradually declined until reaching levels equivalent to Group $210 \mathrm{sec}$ by the fourth session (Extinction Session 4; Group $\times$ Time interaction: $F_{(8,80)}=2.66, P=0.012$; post hoc reveals no difference between Groups 30 and $210 \mathrm{sec}$ at any time bin).

In the savings test following reconditioning, freezing was influenced by the conditioning history (main effect of Group: $\left.F_{(2,20)}=4.66, P=0.022\right)$. Both previously conditioned groups froze significantly more than Group Context Alone, which was conditioned a single time. No differences in freezing were observed between Groups 30 and 210 sec.

An analysis of the asymptotic freezing across each session confirmed the previously described main findings: Group $30 \mathrm{sec}$ froze significantly more than Groups $210 \mathrm{sec}$ and Context Alone during the first extinction session, and Groups 30 and $210 \mathrm{sec}$ froze equivalently more than Context Alone following recondi- tioning (Fig. 4C; Group $\times$ Session interaction: $F_{(10,100)}=4.48$, $P<0.001)$. These findings indicate that postshock context exposure causes a robust and long-lasting loss of conditioned fear but do not support the hypothesis that postshock context exposure causes a more persistent suppression of fear than delayed context exposure.

In two-shock CFC, immediate postshock context exposure is no more effective at reducing fear than delayed exposure In our previous experiment in which the timing of postshock context exposure was manipulated, Groups $24 \mathrm{~h}$ and Contiguous displayed a striking difference in the amount of freezing exhibited during the 180 sec of postshock context exposure. Very little freezing was observed in mice receiving context exposure immediately after the shock, whereas mice receiving context exposure $24 \mathrm{~h}$ after shock displayed robust freezing. The only difference between these conditions was the length of time between shock and postshock context exposure. It is possible that the greater fear attenuation produced by immediate postshock context exposure stems from the relative absence of fear during that period. If, as specified by the peak-end model, the emotional status at the end of an experience strongly influences emotional memory, then high fear during the postshock period should prevent attenuation of context fear. Similarly, Maren and Chang (2006) found that the effectiveness of fear extinction procedures could be enhanced or impaired by decreasing or increasing, respectively, the amount of fear exhibited during the extinction session.

On the basis of these findings, we asked whether immediate context exposure could effectively attenuate context fear under conditions that produce fear during the postshock period. Pilot studies indicated that mice receiving two shocks during a single training session exhibited significant postshock freezing after the second shock. Thus, mice were trained in a two-shock procedure with shocks occurring at 150 and $180 \mathrm{sec}$ after mice were placed into the chamber. Mice received postshock context exposure either immediately after the second shock or $24 \mathrm{~h}$ later. To control for handling effects, Group 1 min was removed from the chamber $30 \mathrm{sec}$ after the shock and then returned to the chamber after $1 \mathrm{~min}$ for the remaining $180 \mathrm{sec}$. Group $24 \mathrm{~h}$ was removed from the chamber $30 \mathrm{sec}$ after the shock, and then replaced for an additional $180 \mathrm{sec} 24 \mathrm{~h}$ later (Fig. 5A).

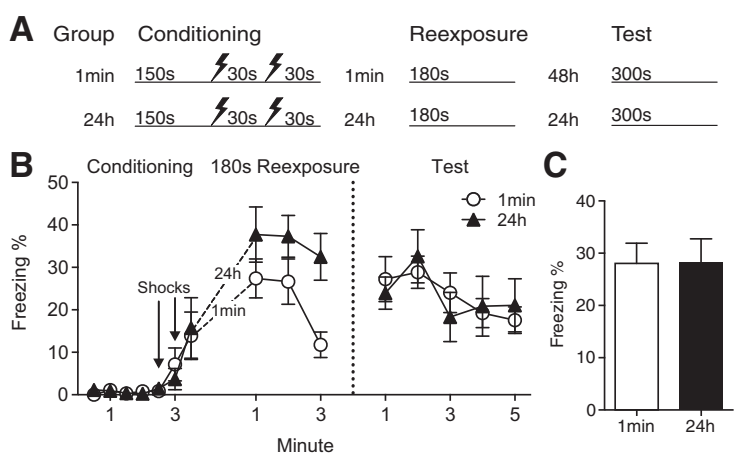

Figure 5. In two-shock CFC, immediate and delayed postshock context exposures have similar effects. (A) Experimental design. (B) Time course of freezing during all phases of the experiment. Both groups displayed freezing during the postshock context exposure, but freezing in Group $24 \mathrm{~h}$ exceeded that of Group 1 min. During the final test of conditioned fear, freezing levels did not differ between the two groups (C) Asymptotic freezing during the final test of context fear did not differ between the two groups. Values are mean percent freezing \pm SEM (Group 1 min: $n=12$, Group 24 h: $n=12$ ). 
As shown in Figure 5B, both the immediate and 24-h groups exhibited freezing during the $180 \mathrm{sec}$ of postshock context exposure. Postshock freezing was again higher in Group $24 \mathrm{~h}$ than Group $1 \mathrm{~min}$ (main effect of group: $F_{(1,22)}=5.18, P=0.033$ ). Importantly, freezing in Group 1 min exceeded that of the previous single-shock groups (e.g., Fig. 3B). During the test session, both groups displayed equivalent levels of freezing $\left(F_{(1,22)}<\right.$ 0.01). Freezing levels during the first $2 \mathrm{~min}$ of the session did not differ (Fig. $5 \mathrm{C} ; t_{(22)}=0.03, P=0.97$ ). This result is consistent with the hypothesis that postshock context exposure is less effective at reducing fear when mice express fear during this period.

\section{Discussion}

By varying the temporal parameters within single-shock CFC we demonstrated that immediate postshock context exposure causes a robust and long-lasting attenuation of conditioned fear. Furthermore, immediate postshock context exposure was more effective at attenuating conditioned fear than an equivalent amount of delayed context exposure. Despite reducing context fear to very low levels, the immediate postshock exposure did not appear to abolish the context-shock association. When mice receiving immediate or delayed postshock context exposure were extinguished to similar levels, the groups displayed equivalent savings upon reconditioning, suggesting that the original learning was at least partially intact.

The effects of varying the postshock context exposure were very different from the effects of varying preshock context exposure. Groups receiving brief postshock context exposure displayed stronger conditioned fear than those receiving extended postshock context exposure, an effect consistent across preshock durations ranging from $10 \mathrm{sec}$ to $10 \mathrm{~min}$. In contrast, the shortest preshock interval ( $2 \mathrm{sec}$ ) yielded less conditioned fear than longer preshock intervals, consistent with the immediate shock deficit. Increasing the preshock context exposure beyond $10 \mathrm{sec}$ had little effect on conditioned fear. The data are inconsistent with a pure rate model of CFC, which would predict equal effects of variation in the postshock and preshock intervals.

The finding that immediate postshock context exposure more strongly attenuated fear than did delayed context exposure appears at odds with recent studies on immediate extinction. A number of studies have evaluated whether the effectiveness of extinction varies as a function of the delay between acquisition and extinction. An initial study by Myers et al. (2006) using fearpotentiated startle reported that extinction within a few minutes after acquisition (immediate extinction) caused a more durable suppression of the conditioned response than did extinction 24 $\mathrm{h}$ after acquisition. However, subsequent studies using aversive (Maren and Chang 2006; Woods and Bouton 2008; Chang and Maren 2009; Archbold et al. 2010; Stafford et al. 2013) and appetitive procedures (Rescorla 2004; Woods and Bouton 2008) in rodents as well as humans (Norrholm et al. 2008; Schiller et al. 2008) failed to observe superiority of immediate extinction. Indeed, in a number of studies immediate extinction was less effective than delayed extinction at suppressing the CR (Rescorla 2004; Maren and Chang 2006; Woods and Bouton 2008; Chang and Maren 2009; Stafford et al. 2013). None of the immediate extinction studies assessed the effect of extinction in the same session as acquisition, as our study did. We could identify only one other study that investigated the effect of postshock context exposure within the same session as CFC acquisition. This study (Lattal and Abel 2001) found no effect, but the levels of conditioned freezing were quite low in groups receiving shock intensities comparable to those in our study, raising the possibility of a floor effect. In our hands, contiguity of acquisition and extinction was not nec- essary to obtain superiority of immediate postshock context exposure. Immediate postshock context exposure was more effective at reducing conditioned fear even when mice were briefly removed from the conditioning chamber in between acquisition and extinction (Fig. 3). Thus, the conflict between our study and previous studies of immediate extinction must be explained by factors other than contiguity of training and extinction.

Another difference between the present study and many others investigating immediate extinction is the conditioning procedure. Most of the previous studies conditioned subjects to discrete auditory or visual cues and did not examine extinction of context fear directly (Cain et al. 2005; Alvarez et al. 2007; Norrholm et al. 2008; Schiller et al. 2008; Woods and Bouton 2008; Huff et al. 2009; Johnson et al. 2010; Kim et al. 2010; MacPherson et al. 2013). It is well established that cued and context fear conditioning recruit distinct neural mechanisms (Kim and Fanselow 1992; Phillips and LeDoux 1992; Maren et al. 1997), raising the possibility that cued and context conditioning are differentially sensitive to immediate extinction. However, two recent studies (Archbold et al. 2010; Stafford et al. 2013) compared the effectiveness of immediate and delayed extinction of context fear and failed to observe superiority of immediate extinction. Thus, the use of contextual versus discrete-cue conditioning does not explain the differences between our findings and those studies failing to observe immediate extinction superiority.

The critical difference between previous studies of immediate extinction and ours may be the level of fear expressed during the extinction session. In the earlier fear conditioning studies that failed to observe immediate extinction superiority, the level of fear exhibited during immediate extinction was as high or higher than that displayed during delayed extinction, because most studies used stronger conditioning procedures involving multiple shocks (one exception is Stafford et al. 2013). In contrast, in our single-shock CFC paradigm, mice displayed very low levels of freezing during the immediate postshock period. Fear appeared to incubate in the hours after training, culminating in much higher levels of freezing when mice were tested for context fear $24 \mathrm{~h}$ after training. These temporal dynamics meant that fear was low during the immediate postshock context exposure and significantly higher during the delayed postshock context exposure. High levels of fear appear to detract from the effectiveness of extinction. Exposing rats to a fear-inducing context shortly before nonreinforced exposure to a conditioned stimulus (CS) impairs extinction (Morris et al. 2005). Similarly, Maren and Chang (2006) found that shocking rats in an alternate context shortly prior to fear extinction reduced the effectiveness of extinction. On the basis of these findings, we hypothesize that the low fear is necessary for immediate extinction to be effective. Consistent with this idea, the one experiment in which Maren and Chang (2006) observed a trend (albeit not statistically significant) toward superiority of immediate extinction was when a weak conditioning procedure was used (single-shock auditory fear conditioning), which led to very low freezing during immediate extinction. Conversely, in our two-shock training procedure, mice displayed robust freezing during the immediate postshock period, and under this condition immediate context exposure was no more effective than delayed context exposure at reducing conditioned fear.

Why might fear attenuate the effects of immediate postshock context exposure? According to the peak-end model, the emotional evaluation of an experience is strongly influenced by the emotional status at the end of the event (Kahneman et al. 1993; Redelmeier et al. 2003). The absence of fear at the end of the conditioning session, as in our single-shock experiments, would lead to a reduction in conditioned fear, whereas the presence of fear at the end of the session (e.g., in the two-shock experiment) should favor the maintenance of conditioned fear. A purely behavioral 
account is also possible. According to stimulus sampling theory, extinction occurs as each individual element of a CS is experienced in the absence of the US (Estes 1955). Freezing during context extinction would presumably reduce the number of contextual elements experienced, thus reducing the effectiveness of the extinction procedure relative to animals that are not freezing. Still another possibility is that the stress response accompanying the higher level of fear arousal during multishock conditioning inhibits extinction. The stress response evoked by fear conditioning may impair function in prefrontal cortical regions involved in extinction (Maren and Quirk 2004; Maren 2014). Acute, uncontrollable stress interferes with prefrontal cortex function in a wide range of tasks (Arnsten 2009). In relation to fear conditioning, electrophysiological studies have shown amygdala activity evoked by presentation of a fear-inducing CS can reduce activity in prefrontal cortex as a function of degree of fear (Garcia et al. 1999). Additionally, exposure to stressors prior to conditioning can impair subsequent extinction (Izquierdo et al. 2006), while anxiolytic doses of cannabinoids have been shown to facilitate extinction of contextual fear memories (Bitencourt et al. 2008). Our findings are consistent with the idea that extinction learning during postshock context exposure is enhanced when fear levels are low.

Why was immediate postshock context exposure more effective at reducing conditioned fear than was delayed context exposure? One possibility is that nonreinforced exposure affects associative strength through different learning mechanisms depending on whether it occurs during acquisition versus after it. Such an idea is embedded in the Gibbon and Balsam (1981) model, which posits that nonreinforced exposure during acquisition figures in setting the associative strength (or, more precisely, US expectancy, $h$ ), whereas, after associative strength is established, nonreinforced exposure drives extinction. The behavioral effect of nonreinforced exposure would presumably vary depending on which mechanism was invoked. A related idea is included in the state classification model (Redish et al. 2007; Gershman et al. 2010), which proposes that extinction can be coded as either a component of acquisition or an independent event, and the behavioral effects of extinction vary depending on which of these two coding schemes is invoked. Our data support the idea that nonreinforced exposure can recruit different behavioral (and presumably neural) mechanisms depending on whether it occurs during acquisition or after it.

Another intriguing possibility is that contextual novelty modulates the efficacy of extinction. Extinction occurring during or in close temporal proximity to acquisition occurs at a time when context novelty is maximal. Novelty modulates various forms of hippocampus-dependent plasticity. Exploration of a novel context can either enhance or impair long-term potentiation in the hippocampus (Xu et al. 1998; Abraham et al. 2002; Li et al. 2003; Straube et al. 2003; Davis et al. 2004) and can strengthen learning in a variety of hippocampus-dependent tasks (Moncada and Viola 2007; Ballarini et al. 2009; Almaguer-Melian et al. 2012). A recent study demonstrated that exposure to a novel context can enhance extinction of CFC (de Carvalho Myskiw et al. 2013). The authors proposed a synaptic tagging mechanism to explain this effect: exposure to a novel context evokes expression of plasticity proteins, which are then captured by synapses potentiated as a result of the extinction procedure. Another possibility is that the novel context evokes dopamine release in the prefrontal cortex (Feenstra and Botterblom 1996; Rebec et al. 1996; Beaufour et al. 2001), where it has been shown to enhance the strength of extinction (Hikind and Maroun 2008; Mueller et al. 2010; Fiorenza et al. 2012; Haaker et al. 2013).

We concluded that immediate postshock context exposure attenuates conditioned fear but does not altogether abolish the as- sociation. Our conclusion is based on the observation that mice given immediate postshock context exposure displayed savings when subsequently reconditioned. That is, the reconditioned mice displayed higher context-elicited freezing than did mice that were conditioned for the first time, and the effect of reconditioning did not differ between groups receiving immediate or delayed postshock context exposure. The presence of savings indicates that some vestige of the original training experience was intact after immediate postshock context exposure. What is unknown is whether this vestige is associative or nonassociative. Although CFC is associative in nature (Fanselow 1986; Sauerhöfer et al. 2012), fear conditioning in mice can also produce significant nonassociative behavioral plasticity, which is evidenced by increases in anxiety-like behavior and the display of fear in response to cues never paired with shock (Kamprath and Wotjak 2004). Thus, the presence of savings after extinction does not definitively demonstrate preservation of the original context-US association, as savings could reflect nonassociative plasticity. Additional experiments are needed to distinguish between these explanations.

It was unexpected that mice acquired CFC with a preshock interval as short as $10 \mathrm{sec}$. In some studies, the 10 -sec preshock interval produces the immediate shock deficit. However, ours is not the first report of robust conditioning with a preshock interval as short as $10 \mathrm{sec}$. Wiltgen et al. (2001) showed that a preshock interval as short as 5 sec produces appreciable levels of conditioned freezing, particularly during the first $2 \mathrm{~min}$ of the test session. Similarly, Bevins and Ayres (1995) observed robust freezing after a 2.5-sec preshock interval. The minimum amount of preshock context exposure required for CFC may vary across species and mouse strain. Many of the original studies of the immediate shock deficit were conducted in rats, and our own laboratory found a preshock interval of $10 \mathrm{sec}$ to be insufficient for CFC in the 129sv/evTac mouse strain (Drew et al. 2010; the current study used C57BL/6J mice).

In summary, we demonstrated that in single-trial CFC, nonreinforced context exposure immediately after the context-shock pairing potently attenuates conditioned fear. The effect of immediate postshock context exposure was greater than that of delayed postshock context exposure. This effect may represent enhanced extinction immediately after training, or may reflect that nonreinforced context exposure during (or immediately following) the conditioning session influences the associative value of the context through a distinct mechanism. The effect of postshock context exposure was present following single-shock CFC but absent after two-shock CFC, which suggests that the effect of immediate postshock context exposure may depend on low levels of fear during the postshock period.

\section{Materials and Methods}

\section{Subjects}

One hundred eighty-two adult male C57BL/6J mice aged 9-12 wk purchased from Jackson Laboratories were used. Mice were housed in groups of four in plastic cages with wood chip bedding and maintained on a $12 \mathrm{~h}$ light/dark cycle (7:00-19:00) in a temperature- and humidity-controlled vivarium. Food and water were provided ad libitum. Experiments were conducted during the light phase. All procedures were approved by the University of Texas at Austin Institutional Animal Care and Use Committee.

\section{Apparatus}

Fear conditioning was conducted in Med Associate conditioning chambers, which were $30.5 \times 24 \times 21 \mathrm{~cm}$ with two aluminum side walls, a Plexiglas door and ceiling, and a white vinyl back wall. Chambers were contained within a larger, sound-attenuating chamber equipped with a fan to provide $\sim 65 \mathrm{~dB}$ ambient 
noise. An overhead white light illuminated the chamber continuously throughout the procedures.

The conditioning context contained a straight stainless steel rod floor (36 rods, spaced $8 \mathrm{~mm}$ from center to center), through which footshocks were delivered. The chamber was cleaned with a $70 \%$ ethanol solution between uses. The chamber was scented with $1 \%$ acetic acid solution in the waste tray below the floor.

\section{Behavioral procedures}

\section{General}

Animals were handled for 3-5 d prior to experimentation. Subjects were transported from the vivarium to a holding room adjacent to the test room at least $1 \mathrm{~h}$ before experimentation. Mice were moved individually to and from the conditioning room in an opaque container. The transport containers were cleaned with a $70 \%$ ethanol solution between uses. After being removed from the chamber, each mouse was returned to the holding room and placed in a holding cage. Once all cagemates completed testing, they were removed from the holding cage and returned to the home cage.

\section{Conditioning}

A single 2-sec $0.75 \mathrm{~mA}$ scrambled footshock delivered through the floor was used as the US. Pre- and postshock intervals varied between experiments. The preshock interval was defined as the amount of time from the closing of the chamber doors until the delivery of the footshock. The postshock interval was defined as the amount of time between the end of the footshock and the opening of the chamber doors to remove the subject. The two-shock procedure (Fig. 5) consisted of US presentations occurring 150 and $180 \mathrm{sec}$ after the mouse was placed in the chamber. For experiments in which mice were removed after $30 \mathrm{sec}$ but returned shortly afterward, mice were placed in their holding cage for $1 \mathrm{~min}$ and then returned to the context for an additional $180 \mathrm{sec}$.

Context fear tests took place 24 or $48 \mathrm{~h}$ after conditioning. Mice were placed in the conditioning context for $5 \mathrm{~min}$ and freezing behavior was assessed.

\section{Reconditioning}

Mice either received a single $2 \mathrm{sec} 0.75-\mathrm{mA}$ footshock $10 \mathrm{sec}$ after placement in the conditioning chamber, or were exposed to the context for $220 \mathrm{sec}$. Beginning $7 \mathrm{~d}$ following training, mice received four daily extinction sessions, consisting of a 5-min exposure to the conditioning chamber. Twenty-four hours after the final extinction session, all mice were reconditioned with a single 2 sec 0.75 -mA footshock $180 \mathrm{sec}$ after placement in the chamber. Mice were removed $30 \mathrm{sec}$ after the shock. Twenty-four hours following reconditioning, conditioned fear was tested by replacing mice into the conditioning chamber for $5 \mathrm{~min}$.

\section{Analysis}

All sessions were video recorded using a near-infrared camera mounted to the interior door of the chamber. The videos were analyzed for freezing behavior with VideoFreeze software recording at 30 frames/sec. We and others (Anagnostaras et al. 2010) have confirmed that the computer scoring correlates highly with manual scoring.

The data were analyzed in two ways. We computed the percent time freezing during each minute of the context test. These data were analyzed with repeated-measures two-way ANOVA, followed with Holm-Sidak's post hoc tests for between-group pairwise comparisons. Because freezing declined over the course of the test sessions, either because of within-session extinction or temporal specificity of freezing, we also analyzed the mean freezing during the first $2 \mathrm{~min}$ of the test sessions, which represented the asymptotic freezing level. These data were analyzed with one- way ANOVA or, for experiments with only two groups, a Student's $t$-test. Significant ANOVA effects were probed using Holm-Sidak's or Dunnet's post hoc tests. Statistical analyses were performed on GraphPad Prism. The $\alpha$ criterion was set at 0.05 in all analyses.

\section{Acknowledgments}

This work was supported by funding from NIH grants MH102595 and MH083943.

\section{References}

Abraham WC, Logan B, Greenwood JM, Dragunow M. 2002. Induction and experience-dependent consolidation of stable long-term potentiation lasting months in the hippocampus. J Neurosci 22: 9626-9634.

Almaguer-Melian W, Bergado-Rosado J, Pavón-Fuentes N, AlbertiAmador E, Mercerón-Martínez D, Frey JU. 2012. Novelty exposure overcomes foot shock-induced spatial-memory impairment by processes of synaptic-tagging in rats. Proc Natl Acad Sci 109: 953-958.

Alvarez RP, Johnson L, Grillon C. 2007. Contextual-specificity of shortdelay extinction in humans: renewal of fear-potentiated startle in a virtual environment. Learn Mem 14: 247-253.

Anagnostaras SG, Wood SC, Shuman T, Cai DJ, Leduc AD, Zurn KR, Zurn JB, Sage JR, Herrera GM. 2010. Automated assessment of Pavlovian conditioned freezing and shock reactivity in mice using the video freeze system. Front Behav Neurosci 4: 1-11.

Archbold GEB, Bouton ME, Nader K. 2010. Evidence for the persistence of contextual fear memories following immediate extinction. Eur J Neurosci 31: 1303-1311.

Arnsten AF. 2009. Stress signalling pathways that impair prefrontal cortex structure and function. Nat Rev Neurosci 10: 410-422.

Ballarini F, Moncada D, Martinez MC, Alen N, Viola H. 2009. Behavioral tagging is a general mechanism of long-term memory formation. Proc Natl Acad Sci 106: 14559-14604.

Barela PB. 1999. Theoretical mechanisms underlying the trial-spacing effect in Pavlovian fear conditioning. J Exp Psychol Anim Behav Process 25: $177-193$.

Beaufour CC, Le Bihan C, Hamon M, Thiébot MH. 2001. Extracellular dopamine in the rat prefrontal cortex during reward-, punishment-and novelty-associated behaviour. Effects of diazepam. Pharmacol Biochem Behav 69: 133-142.

Bevins RA, Ayres JJ. 1995. One-trial context fear conditioning as a function of the interstimulus interval. Anim Learn Behav 23: 400-410.

Bindra D, Cameron L. 1953. Changes in experimentally produced anxiety with the passage of time: incubation effect. J Exp Psychol 45: $197-203$.

Bitencourt RM, Pamplona FA, Takahashi RN. 2008. Facilitation of contextual fear memory extinction and anti-anxiogenic effects of AM404 and cannabidiol in conditioned rats. Eur Neuropsychopharmacol 18: $849-859$.

Blanchard RJ, Fukunaga KK, Blanchard DC. 1976. Environmental control of defensive reactions to footshock. Bull Psychonomic Soc 8: $129-130$.

Cain CK, Godsil BP, Jami S, Barad M. 2005. The L-type calcium channel blocker nifedipine impairs extinction, but not reduced contingency effects, in mice. Learn Mem 12: 277-284.

Chan WYM, Leung HT, Westbrook RF, McNally GP. 2010. Effects of recent exposure to a conditioned stimulus on extinction of Pavlovian fear conditioning. Learn Mem 17: 512-521.

Chang CH, Maren S. 2009. Early extinction after fear conditioning yields a context-independent and short-term suppression of conditional freezing in rats. Learn Mem 16: 62-68.

Davis CD, Jones FL, Derrick BE. 2004. Novel environments enhance the induction and maintenance of long-term potentiation in the dentate gyrus. J Neurosci 24: 6497-6506.

de Carvalho Myskiw J, Benetti F, Izquierdo I. 2013. Behavioral tagging of extinction learning. Proc Natl Acad Sci 110: 1071-1076.

Drew MR, Denny CA, Hen R. 2010. Arrest of adult hippocampal neurogenesis in mice impairs single- but not multiple-trial contextual fear conditioning. Behav Neurosci 124: 446-454.

Estes WK. 1955. Statistical theory of spontaneous recovery and regression. Psychol Rev 62: 145-154.

Fanselow MS. 1986. Associative vs topographical accounts of the immediate shock-freezing deficit in rats: implications for the response selection rules governing species-specific defensive reactions. Learn Motiv 17: 16-39.

Fanselow MS. 1990. Factors governing one-trial contextual conditioning. Anim Learn Behav 18: 264-270. 
Fanselow MS. 2010. From contextual fear to a dynamic view of memory systems. Trends Cogn Sci 14: 7-15.

Fanselow MS, DeCola JP, Young SL. 1993. Mechanisms responsible for reduced contextual conditioning with massed unsignaled unconditional stimuli. J Exp Psychol Anim Behav Process 19: $121-137$.

Feenstra MG, Botterblom MH. 1996. Rapid sampling of extracellular dopamine in the rat prefrontal cortex during food consumption, handling and exposure to novelty. Brain Res 742: 17-24.

Fiorenza NG, Rosa J, Izquierdo I, Myskiw JC. 2012. Modulation of the extinction of two different fear-motivated tasks in three distinct brain areas. Behav Brain Res 232: 210-216.

Garcia R, Vouimba RM, Baudry M, Thompson RF. 1999. The amygdala modulates prefrontal cortex activity relative to conditioned fear. Nature 402: $294-296$.

Gershman SJ, Blei DM, Niv Y. 2010. Context, learning, and extinction. Psychol Rev 117: 197-209.

Gershman SJ, Jones CE, Norman KA, Monfils MH, Niv Y. 2013. Gradual extinction prevents the return of fear: implications for the discovery of state. Front Behav Neurosci 7: 164.

Gibbon J, Balsam P. 1981. Spreading association in time. In Autoshaping and conditioning theory (ed. Locurto CM, Terrace HS, Gibbon J), pp. 219-253. Academic Press, New York.

Haaker J, Gaburro S, Sah A, Gartmann N, Lonsdorf TB, Meier K, Singewald N, Pape HC, Morellini F, Kalisch R. 2013. Single dose of L-dopa makes extinction memories context-independent and prevents the return of fear. Proc Natl Acad Sci 110: E2428-E2436.

Hikind N, Maroun M. 2008. Microinfusion of the D1 receptor antagonist, SCH23390 into the IL but not the BLA impairs consolidation of extinction of auditory fear conditioning. Neurobiol Learn Mem 90: 217-222.

Huff NC, Hernandez JA, Blanding NQ, LaBar KS. 2009. Delayed extinction attenuates conditioned fear renewal and spontaneous recovery in humans. Behav Neurosci 123: 834-843.

Izquierdo A, Wellman CL, Holmes A. 2006. Brief uncontrollable stress causes dendritic retraction in infralimbic cortex and resistance to fear extinction in mice. J Neurosci 26: $5733-5738$.

Johnson JS, Escobar M, Kimble WL. 2010. Long-term maintenance of immediate or delayed extinction is determined by the extinction-test interval. Learn Mem 17: 639-644

Kahneman D, Fredrickson BL, Schreiber CA, Redelmeier DA. 1993. When more pain is preferred to less: adding a better end. Psychol Sci 4: 401-405.

Kamin LJ. 1957. The retention of an incompletely learned avoidance response. J Comp Physiol Psychol 50: 457-460.

Kamprath K, Wotjak CT. 2004. Nonassociative learning processes determine expression and extinction of conditioned fear in mice. Learn Mem 11: $770-786$.

Kiernan MJ, Cranney J. 1992. Immediate-startle stimulus presentation fails to condition freezing responses to contextual cues. Behav Neurosci 106: $121-124$.

Kiernan MJ, Westbrook RF, Cranney J. 1995. Immediate shock, passive avoidance, and potentiated startle: implications for the unconditioned response to shock. Anim Learn Behav 23: 22-30.

Kim JJ, Fanselow MS. 1992. Modality-specific retrograde amnesia of fear. Science 256: 675-677.

Kim SC, Jo YS, Kim IH, Kim H, Choi JS. 2010. Lack of medial prefrontal cortex activation underlies the immediate extinction deficit. J Neurosci 30: $832-837$.

Lattal KM, Abel T. 2001. An immediate-shock freezing deficit with discrete cues: a possible role for unconditioned stimulus processing mechanisms. J Exp Psychol Anim Behav Process 27: 394-406.

Li S, Cullen WK, Anwyl R, Rowan MJ. 2003. Dopamine-dependent facilitation of LTP induction in hippocampal CA1 by exposure to spatial novelty. Nat Neurosci 6: 526-531.

MacPherson K, Whittle N, Camp M, Gunduz-Cinar O, Singewald N, Holmes A. 2013. Temporal factors in the extinction of fear in inbred mouse strains differing in extinction efficacy. Biol Mood Anxiety Disord 3: $1-1$.

Maren S. 2014. Nature and causes of the immediate extinction deficit: a brief review. Neurobiol Learn Mem 113: 19-24.

Maren S, Chang CH. 2006. Recent fear is resistant to extinction. Proc Natl Acad Sci 103: 18020-18025.

Maren S, Quirk GJ. 2004. Neuronal signalling of fear memory. Nat Rev Neurosci 5: 844-852.

Maren S, Aharonov G, Fanselow MS. 1997. Neurotoxic lesions of the dorsal hippocampus and Pavlovian fear conditioning in rats. Behav Brain Res 88: $261-274$.
Moncada D, Viola H. 2007. Induction of long-term memory by exposure to novelty requires protein synthesis: evidence for a behavioral tagging. J Neurosci 27: 7476-7481.

Monfils MH, Cowansage KK, Klann E, LeDoux JE. 2009. Extinction-reconsolidation boundaries: key to persistent attenuation of fear memories. Science 324: 951-955.

Morris RW, Furlong TM, Westbrook RF. 2005. Recent exposure to a dangerous context impairs extinction and reinstates lost fear reactions. J Exp Psychol Anim Behav Process 31: 40-55.

Mueller D, Bravo-Rivera C, Quirk GJ. 2010. Infralimbic D2 receptors are necessary for fear extinction and extinction-related tone responses. Biol Psychiatry 68: 1055-1060.

Myers KM, Ressler KJ, Davis M. 2006. Different mechanisms of fear extinction dependent on length of time since fear acquisition. Learn Mem 13: 216-223.

Norrholm SD, Vervliet B, Jovanovic T, Boshoven W, Myers KM, Davis M, Rothbaum B, Duncan EJ. 2008. Timing of extinction relative to acquisition: a parametric analysis of fear extinction in humans. Behav Neurosci 122: 1016-1030.

Pavlov IP. 1927. Conditioned reflexes. Oxford University Press, London.

Phillips RG, LeDoux JE. 1992. Differential contribution of amygdala and hippocampus to cued and contextual fear conditioning. Behav Neurosci 106: $274-285$.

Rebec GV, Grabner CP, Johnson M, Pierce RC, Bardo MT. 1996. Transient increases in catecholaminergic activity in medial prefrontal cortex and nucleus accumbens shell during novelty. Neurosci 76: 707-714.

Redelmeier DA, Katz J, Kahneman D. 2003. Memories of colonoscopy: a randomized trial. Pain 104: 187-194.

Redish AD, Jensen S, Johnson A, Kurth-Nelson Z. 2007. Reconciling reinforcement learning models with behavioral extinction and renewal: implications for addiction, relapse, and problem gambling. Psychol Rev 114: 784-805.

Rescorla RA. 2004. Spontaneous recovery varies inversely with the training-extinction interval. Learn Behav 32: 401-408.

Rescorla RA, Wagner AR. 1972. A theory of Pavlovian conditioning: variations in the effectiveness of reinforcement and nonreinforcement. In Classical conditioning II: Current research and theory (ed. Black AH, Prokasy WF), pp. 64-99. Appleton-Century-Crofts, New York.

Rudy JW, Barrientos RM, O'Reilly RC. 2002. Hippocampal formation supports conditioning to memory of a context. Behav Neurosci 116: $530-538$.

Rudy JW, Huff NC, Matus-Amat P. 2004. Understanding contextual fear conditioning: insights from a two-process model. Neurosci Biobehav Rev 28: $675-685$.

Sauerhöfer E, Pamplona FA, Bedenk B, Moll GH, Dawirs RR, von Hörsten S, Wotjak CT, Golub Y. 2012. Generalization of contextual fear depends on associative rather than non-associative memory components. Behav Brain Res 233: 483-493.

Schiller D, Cain CK, Curley NG, Schwartz JS, Stern SA, LeDoux JE, Phelps EA. 2008. Evidence for recovery of fear following immediate extinction in rats and humans. Learn Mem 15: 394-402.

Schiller D, Monfils MH, Raio CM, Johnson DC, LeDoux JE, Phelps EA. 2010. Preventing the return of fear in humans using reconsolidation update mechanisms. Nature 463: 49-53.

Stafford JM, Maughan DK, Ilioi EC, Lattal KM. 2013. Exposure to a fearful context during periods of memory plasticity impairs extinction via hyperactivation of frontal-amygdalar circuits. Learn Mem 20: $156-163$.

Straube T, Korz V, Frey JU. 2003. Bidirectional modulation of long-term potentiation by novelty-exploration in rat dentate gyrus. Neurosci Lett 344: $5-8$.

Varey C, Kahneman D. 1992. Experiences extended across time: evaluation of moments and episodes. J Behav Decis Mak 5: 169-185.

Westbrook RF, Good AJ, Kiernan MJ. 1994. Effects of the interval between exposure to a novel environment and the occurrence of shock on the freezing responses of rats. Q J Exp Psychol B 47: 427-446.

Wiltgen BJ, Sanders MJ, Behne NS, Fanselow MS. 2001. Sex differences, context preexposure, and the immediate shock deficit in Pavlovian context conditioning with mice. Behav Neurosci 115: 26-32.

Woods AM, Bouton ME. 2008. Immediate extinction causes a less durable loss of performance than delayed extinction following either fear or appetitive conditioning. Learn Mem 15: 909-920.

Xu L, Anwyl R, Rowan MJ. 1998. Spatial exploration induces a persistent reversal of long-term potentiation in rat hippocampus. Nature 394: 891-894.

Received August 6, 2014; accepted in revised form October 5, 2014. 


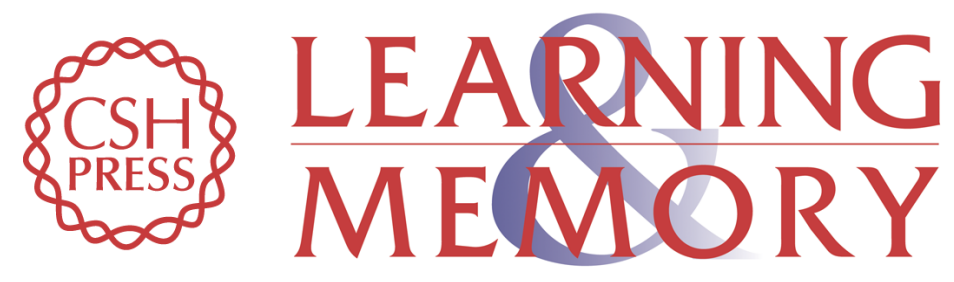

\section{Potent attenuation of context fear by extinction training contiguous with acquisition}

Brian E. Bernier, Anthony F. Lacagnina and Michael R. Drew

Learn. Mem. 2015, 22:

Access the most recent version at doi:10.1101/Im.036673.114

References This article cites 71 articles, 21 of which can be accessed free at: http://learnmem.cshlp.org/content/22/1/31.full.html\#ref-list-1

Creative This article is distributed exclusively by Cold Spring Harbor Laboratory Press for the Commons License first 12 months after the full-issue publication date (see

http://learnmem.cshlp.org/site/misc/terms.xhtml). After 12 months, it is available under a Creative Commons License (Attribution-NonCommercial 4.0 International), as described at http://creativecommons.org/licenses/by-nc/4.0/.

Email Alerting Receive free email alerts when new articles cite this article - sign up in the box at the Service top right corner of the article or click here. 